\title{
Reference Values for Osmolal Gap in healthy Subjects and in medical Inpatients.
}

\begin{abstract}
Methanol and ethylene glycol poisonings are associated with high morbidity and mortality rates if treatment is not initiated early. Since few hospitals measure these toxic alcohols on a $24 / 7$ basis, calculation of the osmolal gap (OG) is an important diagnostic tool. The reference value for the OG lacks consensus. We therefore wanted to update the reference value for OG in presumed healthy subjects and study OG values in internal medicine patients. The OG was calculated in 285 patients at the Medical Clinic at Oslo University Hospital, and in 118 healthy blood donors at Vestfold Hospital Trust. OG was calculated by the formula: $O G=$ Measured osmolality - calculated osmolality $((1,86 \times$ s-sodium + s-glucose + s-urea $) / 0,93)$ $\mathrm{mOsm} / \mathrm{kgH}_{2} \mathrm{O}$. In the patients, median $\mathrm{OG}$ was $0 \mathrm{mOsm} / \mathrm{kgH}_{2} \mathrm{O}$ (interquartile range [-3] - 3 $\mathrm{mOsm} / \mathrm{kgH}_{2} \mathrm{O}$, range [-16] - $103 \mathrm{mOsm} / \mathrm{kgH}_{2} \mathrm{O}$ ). When corrected for one outlier, the central $95 \%$ interval for OG was -10 to 20 . The healthy blood donors had a median OG of $-1 \mathrm{mOsm} /$ $\mathrm{kgH}_{2} \mathrm{O}$ (interquartile range [-3] $-1 \mathrm{mOsm} / \mathrm{kgH}_{2} \mathrm{O}$, range [-13] $-8 \mathrm{mOsm} / \mathrm{kgH}_{2} \mathrm{O}$ ). When corrected for outliers, the reference range was -6 to $5 \mathrm{mOsm} / \mathrm{kg} \mathrm{H}_{2} \mathrm{O}$.. Based on results from a healthy population, we suggest a reference value for the $\mathrm{OG}$ of $\leq 5 \mathrm{mOsm} / \mathrm{kg} \mathrm{H} \mathrm{H}_{2} \mathrm{O}$, but also recommend, based on our results from medical inpatients, to keep todays practice for suspecting poisoning with toxic alcohols at an elevated OG of $\geq 20 \mathrm{mOsm} / \mathrm{kgH}_{2} \mathrm{O}$.
\end{abstract}

Keywords: Reference values; osmolar concentration; ethylene glycol; methanol; diagnostic tests, routine

\section{Introduction}


Metabolic acidosis has many causes and may be a diagnostic challenge [1]. The most common cause is lactic acidosis caused by hypoperfusion and tissue ischemia, while lactic acidosis caused by metabolic interference is less common $[2,3]$. In cases of diabetic ketoacidosis and renal failure, causation is well known and rarely a diagnostic challenge.

When consuming toxic alcohols such as methanol and ethylene glycol (antifreeze), metabolic acidosis gradually develops due to their acidic metabolites, formic acid and glycolic acid, respectively (Figure 1) [4, 5]. [Figure 1 near here] A method for simple and rapid detection of methanol, ethylene glycol or their acidic metabolites is not yet commercially available. The analyses of methanol og ethylene glycol is performed by eight and six Norwegian hospital laboratories respectively[6, 7]. A dry-chemistry method for formate detection has been published, but a short shelf-life has so far limited further commercial development [8]. Todays methods by e.g. gas chromatography mass spectrometry (GC-MS) would confirm the diagnosis in approximately 12-24 hours. Specific/antidote treatment, if indicated, should be initiated as soon as possible to reduce the severity of the outcome $[4,5]$. Therefore, lifesaving treatment must be initiated based on clinical assessment and/or indirect diagnostics via the calculation of the osmolal gap (OG) as a surrogate measure for the presence of toxic alcohols. As shown in Table 1, alcohols such as methanol and ethylene glycol, due to their low molecular weight properties, will make a significant osmolal contribution and increase the OG, particularly in the early stages [9]. [Table 1 near here] Ethanol, which is often ingested at the same time, may also affect the OG, and must therefore be corrected for. The calculated anion gap (AG) may be used as a surrogate measure for the metabolites [1]. The AG has, however, limitations at high concentrations of formate $(>20 \mathrm{mmol} / \mathrm{L})$ because of lactate production through the so-called "circulus hypoxicus", the process where part of the 
mechanism consists of format inhibiting mitocondrial respiration leading to a secondary lactic acidosis [3] .

A theoretically sound and well established formula for calculated osmolality is $(1.86 \times \mathrm{s}-$ sodium + s-glucose + s-urea) $/ 0.93 \mathrm{mOsm} / \mathrm{kg} \mathrm{H}_{2} \mathrm{O}[10,11]$. This formula takes into account that 1.86 is the osmotic coefficient of sodium chloride, and that water normally constitutes $93 \%$ of plasma [10]. Although simpler formulae exist for bedside calculations [12], the present formula[10] is the most widely used in our region and it can easily be implemented in the Laboratory Information System for automatic request and calculation.

Because measurement of the OG is still an important part of the diagnostic work on suspected toxic alcohol ingestion, we have conducted a study to update the reference interval for presumed healthy subjects and report OG values in internal medicine patients.

\section{Materials and methods}

In this study a retrospective data extraction was performed using the laboratory information system Swisslab (SWISSLAB DITS GmbH, Berlin, Germany). The data extraction resulted in 285 inpatients from all Medical departments at Oslo University Hospital HF (OUS), Ullevaal, with measured osmolality and calculated OG, in 2015 and 2016. The patients' charts were not accessed and diagnoses were thus not recorded. Registered variables were age, gender, osmolality, and OG which is automatically calculated. In order to exclude patients with suspected alcohol poisoning, patients in whom s-ethanol was requested during admission were excluded. In cases of repeated OG calculations during admission, only the first measured value was included in the analyses. 
At Oslo University Hospital, s-osmolality was measured by freezing point depression with Fiske 210 manual osmometer (Advanced Instruments, Norwood, MA, USA) with an analytical coefficient of variation of $1.5 \%$. All samples were analyzed in duplicates and the mean was reported. Sodium was analyzed by ion-selective electrodes with automatic dilution of serum by Roche Cobas 8000 ISE module (Roche Diagnostics, Basel, Switzerland), urea was analyzed by kinetic method with urease and glutamate dehydrogenase by Roche Cobas 8000 c702 (Roche Diagnostics, Basel, Switzerland), and glucose was analyzed by enzymatic method with hexokinase by Roche Cobas 8000 c702 (Roche Diagnostics, Basel, Switzerland).

Statistical analyses were performed with the SPSS version 23.0 (IBM Corp., Armonk, NY, USA). Age, OG and osmolality had non-normal distributions, and non-parametric statistical analyses were therefore used and data are presented as median (interquartile range) unless otherwise stated. The central 95\% interval for OG was calculated using the bootstrap technique according to the IFCC recommendations, using the software RefVal version 4.11 [13]. Any outliers were removed by Dixon's and/or Horn's algorithms [14-16]. The study was approved by the Data Protection Officer at Oslo University Hospital HF. Approval was not obtained by the regional ethics committee as this was a laboratory quality study.

At Vestfold Hospital Trust, osmolality was analyzed and calculated for 118 healthy blood donors in 2014. The program RefVal version 4.10-beta was used to calculate the reference range. Outliers were removed by Horn's algorithm. S-osmolality was measured by freezing point depression with the fully automated osmometer $\mathrm{A}_{2} \mathrm{O}$ Advanced Automated Osmometer (Advanced Instruments, Norwood, MA, USA) with an analytical variation coefficient of 1.5\%. Sodium, urea and glucose were analysed using dry-slide technology on Vitros 5.1 (Ortho-Clinical Diagnostics, USA) with reagents from the supplier. 
At both hospitals, OG was calculated by the formula; measured osmolality - calculated osmolality $(1.86 \times$ s-sodium + s-glucose + s-urea $) / 0.93 \mathrm{mOsm} / \mathrm{kg} \mathrm{H}_{2} \mathrm{O}$.

Due to instrument breakdown during the study period, it was not possible to perform a method comparison between the Fiske 210 osmometer at Oslo University Hospital and the automated $\mathrm{A}_{2} \mathrm{O}$ osmometer currently in use in Vestfold. However, a previous comparison ( $\mathrm{n}=31$ samples) between the Fiske 210 and $\mathrm{A}_{2} \mathrm{O}$ performed at Vestfold Hospital trust Vestfold revealed a non-significant bias of $3 \%$ at $295 \mathrm{mOsm} / \mathrm{kg} \mathrm{H}_{2} \mathrm{O}$ (Deming regression: $\mathrm{A}_{2} \mathrm{O}=(-$ $3.571)+0.982 *$ Fiske) with a correlation coefficient $r=0.994$ (2019 NN ; unreferenced).

\section{Results}

The 285 patients at OUS had a median age of 66 years (interquartile range 50-80 years, range 18-98 years) and $132(46 \%)$ of the patients were women. Median osmolality was 295 $\mathrm{mOsm} / \mathrm{kg} \mathrm{H}_{2} \mathrm{O}$ (interquartile range 285 - 308, range 235 - $413 \mathrm{mOsm} / \mathrm{kg} \mathrm{H}_{2} \mathrm{O}$ ). Median OG was $0 \mathrm{mOsm} / \mathrm{kg} \mathrm{H}_{2} \mathrm{O}$ (interquartile range [-3] - $3 \mathrm{mOsm} / \mathrm{kg} \mathrm{H}_{2} \mathrm{O}$, range [-16] - $103 \mathrm{mOsm} / \mathrm{kg}$ $\mathrm{H}_{2} \mathrm{O}$ ) (Figure 2). [Figure 2 near here]

When calculating the central 95\% interval with RefVal, one extreme outlier was first excluded by Dixon's method $\left(\mathrm{OG}>100 \mathrm{mOsm} / \mathrm{kg} \mathrm{H}_{2} \mathrm{O}\right)$. The central 95\% interval for $\mathrm{OG}$ in 284 patients was -10 to $20 \mathrm{mOsm} / \mathrm{kg} \mathrm{H}_{2} \mathrm{O}$ (90\% CI: -13 to -9 and 17 to 30$)$. Of note, the RefVal program suggested 22 possible additional outliers by Horn's algorithm. When these values were excluded, the central $95 \%$ interval in 262 patients was -8 to $13 \mathrm{mOsm} / \mathrm{kg} \mathrm{H}_{2} \mathrm{O}$ (90\% CI: -8 to -7 and 10 to 14 ; Figure 2). 
The 118 healthy blood donors at Vestfold Hospital Trust (Figure 3) had a median OG of -1 $\mathrm{mOsm} / \mathrm{kg} \mathrm{H} \mathrm{H}_{2} \mathrm{O}$ (interquartile range [-3] - $1 \mathrm{mOsm} / \mathrm{kg} \mathrm{H}_{2} \mathrm{O}$, range [-13] - $8 \mathrm{mOsm} / \mathrm{kg} \mathrm{H}_{2} \mathrm{O}$ ). [Figure 3 near here] When calculating the reference range with RefVal, 3 outliers were excluded using Horn's algorithm. The reference interval in 115 healthy blood donors was -6 to $5 \mathrm{mOsm} / \mathrm{kg} \mathrm{H}_{2} \mathrm{O}$, with central 95 percentile for s-osmolality of 282-300 $\mathrm{mOsm} / \mathrm{kg} \mathrm{H}_{2} \mathrm{O}$.

\section{Discussion}

The central $95 \%$ interval for OG for the patient population was -10 to $20 \mathrm{mOsm} / \mathrm{kg} \mathrm{H}_{2} \mathrm{O}$. For the healthy population, the reference interval was -6 to $5 \mathrm{mOsm} / \mathrm{kg} \mathrm{H}_{2} \mathrm{O}$. The results show that one can expect to find a higher OG in the non-poisoned medical patient than in healthy subjects. This is in line with results from a previous study where OG in the healthy population was measured up to $5 \mathrm{mOsm} / \mathrm{kgH}_{2} \mathrm{O}$ [10]. Previously published central $95 \%$ interval for OG in emergency medical patients at OUS was -9 to $19 \mathrm{mOsm} / \mathrm{kg} \mathrm{H}_{2} \mathrm{O}$ [11].

Internationally, various formulas and reference ranges are in use. Previously, the recommended upper normal limit for OG was $10 \mathrm{mOsm} / \mathrm{kg} \mathrm{H}_{2} \mathrm{O}[10,17]$. Recent studies have shown that higher values may be expected in non-poisoned medical patients in the Emergency Department, and a decision limit of $>25 \mathrm{mOsm} / \mathrm{kg} \mathrm{H} \mathrm{H}_{2} \mathrm{O}$ has been argued, to initiate specific treatment in patients with suspected methanol and/or ethylene glycol poisoning [1,9]. Raising the decision limit for OG increases the specificity, but decreases the sensitivity of the method, especially for ethylene glycol which has less osmolal contribution than methanol (Table 1). Lower sensitivity may potentially delay necessary life-saving treatment. One study calculated the sensitivity of the presence of toxic alcohols at $\mathrm{OG} \geq 5$ and $\geq 10 \mathrm{mOsm} / \mathrm{kg} \mathrm{H} \mathrm{H}_{2} \mathrm{O}$ respectively, and found that it decreased from $96 \%$ to $91 \%$, while specificity increased from $56 \%$ to $79 \%[12]$. 
Todays practice at OUS is to consider antidote treatment at $\mathrm{OG} \geq 20 \mathrm{mOsm} / \mathrm{kg} \mathrm{H}_{2} \mathrm{O}$, when methanol and/or ethylene glycol poisoning cannot be excluded. A prerequisite is that a possible osmolal contribution from ethanol is deducted. The patient's clinical condition is the leading factor in the assessment. Concomitant presence of metabolic acidosis which cannot be explained otherwise, especially severe acidosis, strengthens the indication for treatment with antidotes. In methanol poisoning, in addition to a typical clinical presentation with hyperventilation, nausea or vomiting and visual disturbances, pseudopapillitis can be found with ophthalmoscopy [4]. In ethylene glycol poisoning, the central nervous system, the cardiopulmonary system and the kidney will typically be affected, and calcium oxalate crystals may be detected by urine microscopy [5]. When smaller amounts of toxic alcohol are consumed, or when measuring late in the course of intoxication, OG can be measured within the reference range, even in fatal cases, as almost all of the alcohol is metabolised to its toxic acidic metabolite.

The lower 2.5 percentile value of $\mathrm{OG}$ in our patient material was $-10 \mathrm{mOsm} / \mathrm{kg} \mathrm{H}_{2} \mathrm{O}$. A patient may therefore have an increase in $\mathrm{OG}$ of up to $30 \mathrm{mOsm} / \mathrm{kg} \mathrm{H}_{2} \mathrm{O}$ between two measurements and still have an OG value of $\leq 20 \mathrm{mOsm} / \mathrm{kg} \mathrm{H}_{2} \mathrm{O}$. Since antidote treatment, also late in the course of poisoning, may limit the extent of sequela and improve patient outcomes, such treatment should be considered by clinical suspicion even without a clearly elevated OG $[4,5]$.

In the data extraction from medical patients at OUS, retrospective reviews have provided access to laboratory analyses, but not to patient records. Therefore, the patients' diagnoses are not known and it cannot be ruled out that patients included in the study were intoxicated with ethanol, methanol, ethylene glycol or another alcohol. An attempt was made to control for this 
by excluding patients in whom a doctor had ordered ethanol analysis during their stay. It is therefore considered less likely that alcohol poisoning is among the diagnoses of the included patients. Comparing these results to the results of the excluded population would be beneficial. However, few proven medical patients were found in the excluded population, partly due to the fact that only one requisition code is used at the emergency department. OG measurements from this population are therefore not presented.

An extreme outlier with $\mathrm{OG}$ of $>100 \mathrm{mOsm} / \mathrm{kg} \mathrm{H}_{2} \mathrm{O}$ was removed. In addition, the RefVal program suggested 22 possible outliers by Horn's algorithm. If these values were excluded, the central $95 \%$ interval in 262 patients was -8 to $13 \mathrm{mOsm} / \mathrm{kg} \mathrm{H}_{2} \mathrm{O}$. As the study is retrospective we cannot outrule that these 22 patients actually were intoxicated or represent a different patient population (i.e. not internal medicine patients) as we did not have access to patients' diagnoses. A central 95\% interval of -8 to $13 \mathrm{mOsm} / \mathrm{kg} \mathrm{H}_{2} \mathrm{O}$ may suggest a decision limit for antidote treatment below $20 \mathrm{mOsm} / \mathrm{kg} \mathrm{H}_{2} \mathrm{O}$. However, if the decision limit is set too low, it will be non-expedient, resulting in unnecessary and costly treatment of many patients. We therefore argue to maintain current practice with a decision limit for OG of $>20$ $\mathrm{mOsm} / \mathrm{kg} \mathrm{H}_{2} \mathrm{O}$ for considering antidote treatment, at least in patients with concomitant metabolic acidosis. Values below this, however, do not exclude poisoning.

Poisoning with methanol and ethylene glycol are serious conditions with high morbidity and mortality rates. The time aspect is important, as rapid start-up of the correct treatment improves the prognosis considerably. Treatment with fomepizole is costly and it is very advantageous that s-osmolality and OG results are available before treatment is started. This depends on rapid response time between ordering the test and receiving the results for sosmolality, and should therefore be part of the 24/7 emergency services in all hospitals where these poisonings may occur. 
It should be emphasized that osmolality must be measured by a freezing-point depression method, and not by a vapor-pressor method used in some countries $[4,18]$. The latter method, also used in some blood gas machines, will not detect the increased osmolality caused by the volatile alcohols, and thus give a false negative result with potential fatal consequences [18].

\section{Conclusions:}

Based on our data from a healthy population we suggest a reference value for the $\mathrm{OG}$ of $\leq 5$ $\mathrm{mOsm} / \mathrm{kg} \mathrm{H} \mathrm{H}_{2} \mathrm{O}$. Considering the clinical importance of $\mathrm{OG}$ in assessment of poisoning with toxic alcohols and based on our study of medical inpatients, we also suggest to keep todays practice of suspecting poisoning with methanol or ethylene glycol in metabolic acidosis of unknown origin and elevated $\mathrm{OG}\left(>20 \mathrm{mOsm} / \mathrm{kg} \mathrm{H}_{2} \mathrm{O}\right)$. Toxic alcohol poisoning may be present even with a normal OG. Calculation of the OG is still important for rapid diagnosis and treatment of these poisonings. Therefore, a short turnaround time for the calculation of OG is recommended, as well as specific analyses to confirm the diagnosis.

\section{Acknowledgements:}

The authors thank biomedical laboratory scientist and head of the Unit for Biochemistry at the Department of Medical Biochemistry at OUS, Laila Fure, and her co-workers, for valuable comments on the article and performing the analytical work on the patient samples at OUS.

Declaration of interests: The authors report no conflicts of interest. 
Table 1. Osmolal contribution and molecular weight for different agents (modified table) [9].

\begin{tabular}{|c|c|c|}
\hline Agent & $\begin{array}{l}\text { Osmolal contribution } \\
\left(\mathrm{mOsm} / \mathrm{kgH}_{2} \mathrm{O}\right) \text { per } 1 \mathrm{~g} / \mathrm{L} \\
\text { concentration }\end{array}$ & $\begin{array}{l}\text { Molecular weight } \\
\text { (g/mol) }\end{array}$ \\
\hline Methanol & 34 & 32 \\
\hline Ethanol & 24 & 46 \\
\hline Acetone * & 19 & 58 \\
\hline Isopropanol & 18 & 60 \\
\hline Ethylene glycol & 17 & 62 \\
\hline
\end{tabular}

*May be present in ketoacidosis and isopropanol intoxication (metabolite) 


\section{Figure legends:}

Figure 1. Methanol and ethylene glycol are metabolized to formic acid and glycolic acid. Fomepizole and ethanol inhibits this metabolism through competitive inhibition of the enzyme alcohol dehydrogenase (Modified figure) [1]

Figure 2. Osmolal gap measured in 285 medical inpatients at Oslo University Hospital.

Figure 3. Osmolal gap measured in 118 healthy blood donors at Vestfold Hospital Trust. 


\section{References}

1. Hovda KE, Hunderi OH, Ovrebo S, Jacobsen D. [Diagnosis in metabolic acidosis of unknown origin]. Tidsskr Nor Laegeforen 2004;124:3203-5.

2. Kraut JA, Madias NE. Metabolic acidosis: pathophysiology, diagnosis and management. Nat Rev Nephrol 2010;6:274-85.

3. Drangsholt E, Vangstad M, Zakharov S, Hovda KE, Jacobsen D. The Hypothesis of Circulus Hypoxicus and Its Clinical Relevance in Patients With Methanol Poisoning - An Observational Study of 35 Patients. Basic Clin Pharmacol Toxicol 2018;123:749-55.

4. Hovda KE, McMartin K, Jacobsen D. Methanol and Formaldehyde. In: Brent J, Burkhart K, Dargan PI, Hatten B, Mégarbane B, Palmer RB, et al., editors. Critical care toxicology : diagnosis and management of the critically poisoned patient. 2. ed. Cham: Springer; 2017. p. 1769-86.

5. Hovda KE, McMartin K, Jacobsen D. Ethylene Glycol and Other Glycols. In: Brent J, Burkhart K, Dargan PI, Hatten B, Mégarbane B, Palmer RB, et al., editors. Critical care toxicology : diagnosis and management of the critically poisoned patient. 2 . ed. Cham: Springer; 2017. p. 1743-60.

6. Farmakologiportalen [Internet] Etylenglykol. 2018 Sep 28 [cited 2019 Sep 4];

Available from: http://www.farmakologiportalen.no/content/555/Etylenglykol

7. Farmakologiportalen [Internet] Metanol. 2018 Okt 1 [cited 2019 Sep 4];

Available from: http://www.farmakologiportalen.no/content/648/Metanol

8. Hovda KE, Gadeholt G, Evtodienko V, Jacobsen D. A novel bedside diagnostic test for methanol poisoning using dry chemistry for formate. Scand J Clin Lab Invest 2015;75:610-4.

9. Aabakken L, Enger E, Jacobsen D, Stromme JH. [Metabolic acidosis--a diagnostic challenge]. Tidsskr Nor Laegeforen 1994;114:331-4.

10. Glasser L, Sternglanz PD, Combie J, Robinson A. Serum osmolality and its applicability to drug overdose. Am J Clin Pathol 1973;60:695.

11. Aabakken L, Johansen KS, Rydningen EB, Bredesen JE, Ovrebo S, Jacobsen D. Osmolal and anion gaps in patients admitted to an emergency medical department. Hum Exp Toxicol 1994;13:131-4.

12. Lepeytre F, Ghannoum M, Ammann H, Madore F, Troyanov S, Goupil R, Bouchard J. Formulas for Calculated Osmolarity and Osmolal Gap: A Study of Diagnostic Accuracy. Am J Kidney Dis 2017:31.

13. Solberg HE. The IFCC recommendation on estimation of reference intervals. The RefVal program. Clin Chem Lab Med 2004;42:710-4.

14. Dixon WJ. Processing Data for Outliers. Biometrics 1953;9:74-89.

15. Horn PS, Feng L, Li Y, Pesce AJ. Effect of outliers and nonhealthy individuals on reference interval estimation. Clin Chem 2001;47:2137-45.

16. Solberg HE, Lahti A. Detection of outliers in reference distributions:

performance of Horn's algorithm. Clin Chem 2005;51:2326-32.

17. Dargan P. Acid-base and electrolyte disturbances in the poisoned patient. In:

Bateman N, editor. Oxford desk reference : Toxicology. Oxford: Oxford University Press; 2014. p. 75-6.

18. Jacobsen D, McMartin KE. Antidotes for methanol and ethylene glycol poisoning. J Toxicol Clin Toxicol 1997;35:127-43. 


\section{Ethanol}

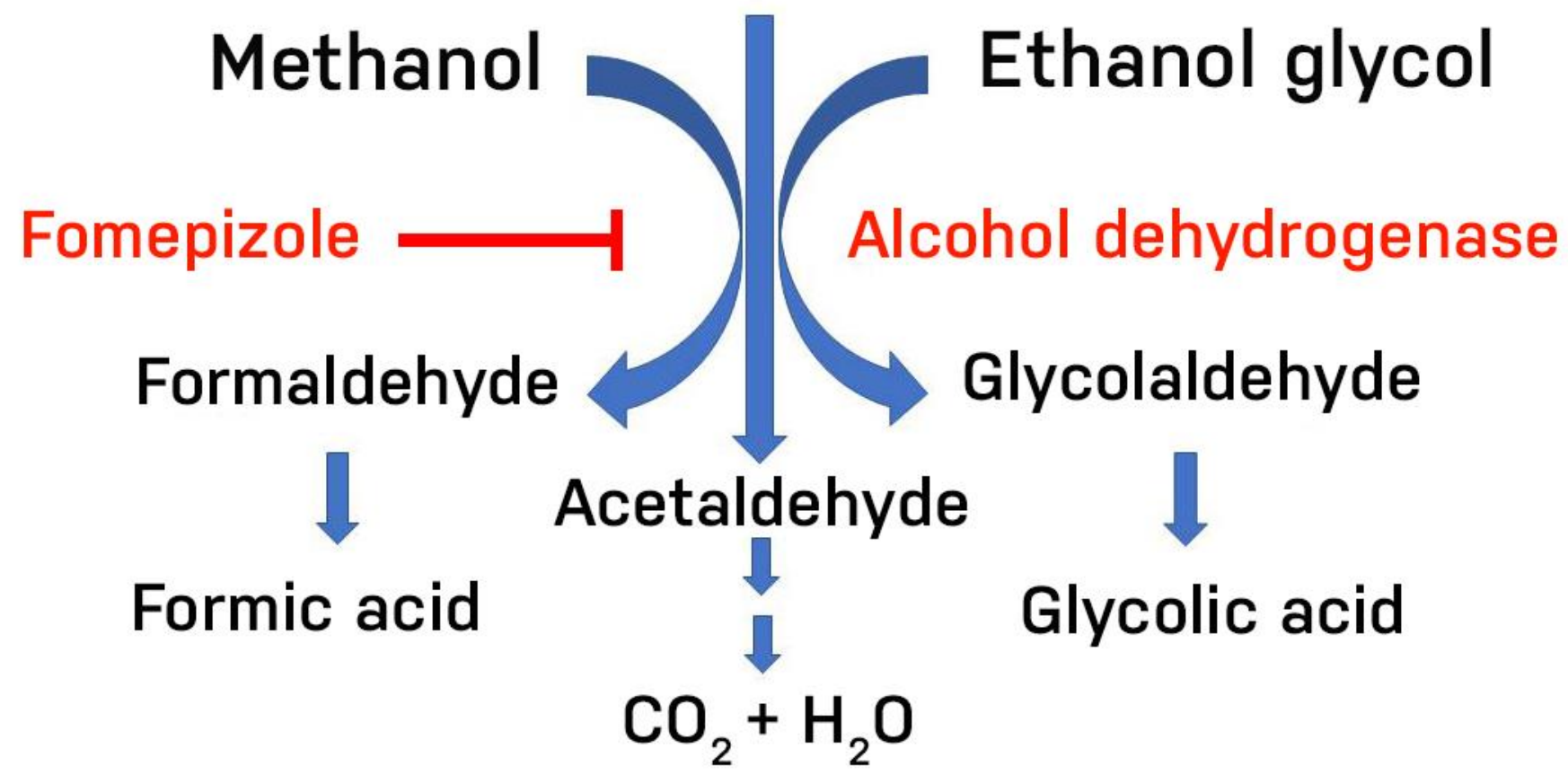




$$
1
$$




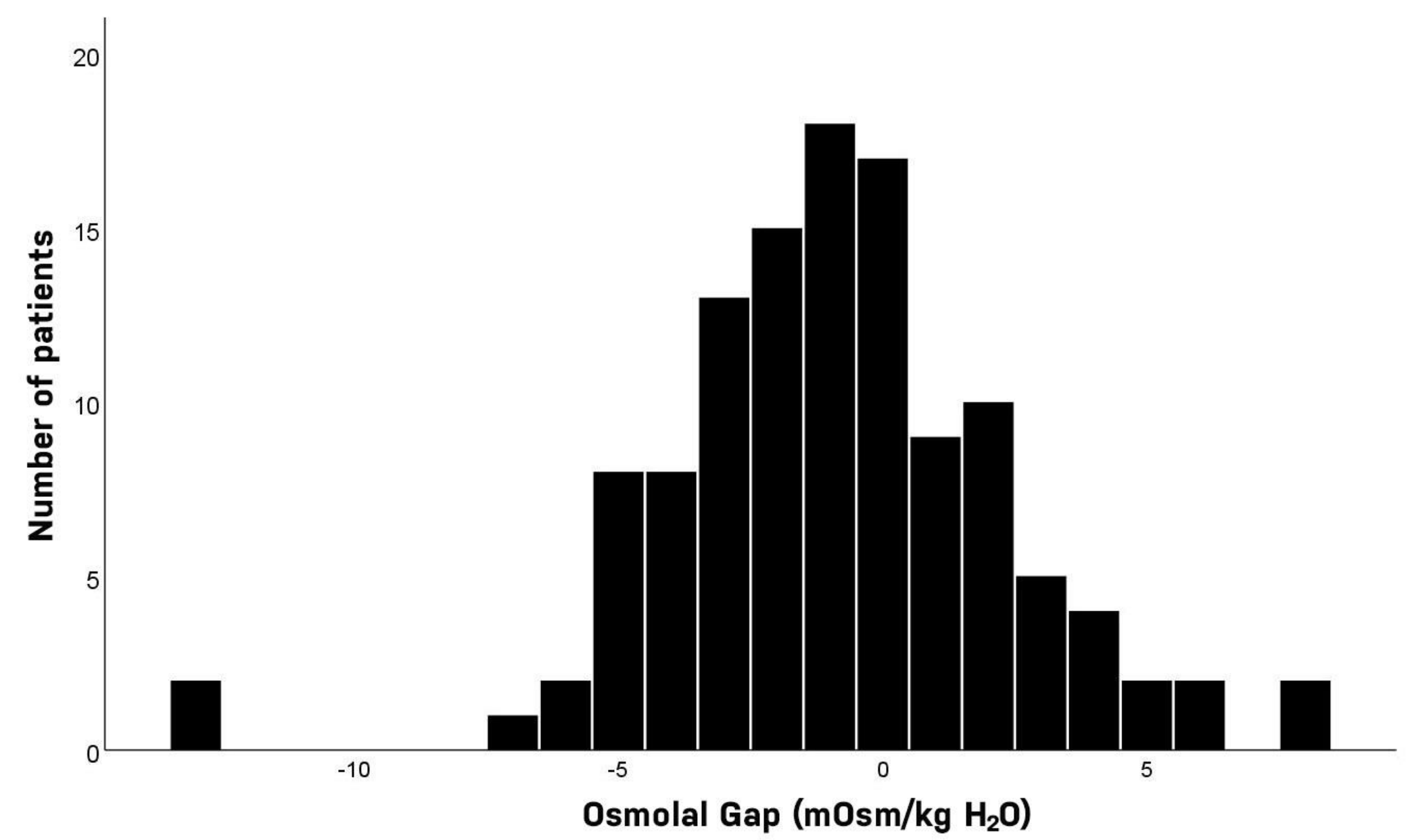

